\title{
Analysis of Materials Selection for Electromagnetic Railguns Chuantong $\mathrm{Du}^{1, \text { a }}$ \\ Shijiazhuang Mechanical Engineering College, Shijiazhuang, Hebei 050003 China \\ a13503219757@163.com
}

Keywords: Materials Selection, Railgun, Layered Materials.

\begin{abstract}
The study of armature and rail materials of electromagnetic railgun is the key technology to solve the failure problems of launcher. The paper focuses on the principles and methods of materials selection of railgun and introduce the research progress of layered materials. Besides, the future development trends are presented.
\end{abstract}

\section{Introduction}

Electromagnetic railgun is a new concept kinetic energy weapon using electromagnetic energy to drive armature with current to hypervelocity. Compared with the conventional artillery, it has the advantages of higher velocity, stronger power, higher safety, easier control and higher cost-effectiveness. It will play a great strategic and tactical application value in the future war ${ }^{[1]}$. The operating principle of electromagnetic railgun is shown in Fig.1, the armature or projectile is placed between the rails and ejected by the Lorens magnetic force.

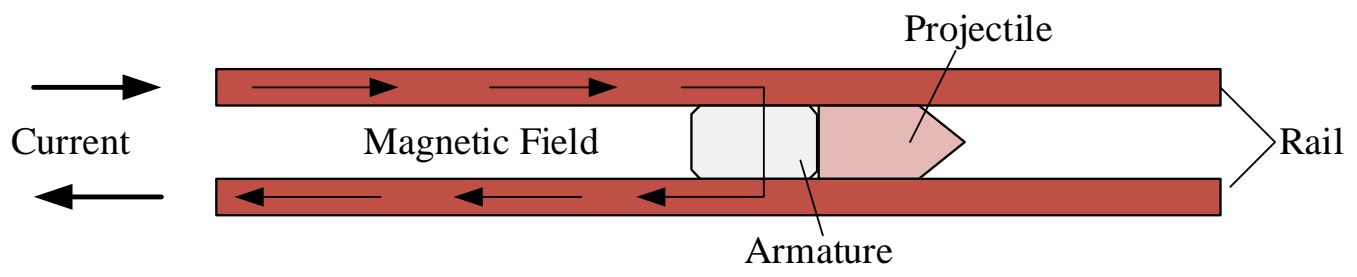

Fig. 1 The schematic diagram of electromagnetic railgun

In the process of electromagnetic railgun firing the armature, the condition of sliding electrical contact between rails and armature is terrible. There will be complex mechanical, thermal, electrical function and powerful impacting force between rails and armature, resulting in failure features, such as materials softening, wear, gouge and erosion. The study of materials of electromagnetic railgun becomes one of the key techniques to solve the problems of railgun.

\section{Materials Selection Principle}

\subsection{Solid Armature}

Solid armatures are metal material mostly, the performance goal of which is to achieve the best state of electrical contacts in the condition of maintaining minimum contact pressure between the rails and armature.In fact, electrical contact is composed of discrete points, which make up the effective contact ${ }^{[2]}$, as is shown in Fig.2.

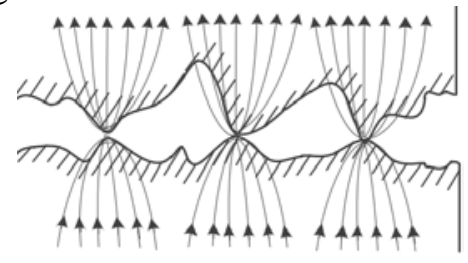

Fig.2 The actual contact surface

Contact points will shift from low voltage to high voltage with the high temperature in the process of electromagnetic railgun operating, resulting in serious erosion. The selection of materials can significantly reduce the temperature of contact points, one of the effective measures to improve the electric contact performance between the rails and armature. The analysis of the principle of 
armature generating heat is as follows.

Assuming that the current flows through the armature uniformly, the loss caused by ohmic heating will equal the Joule heating of the armature material, the formula is shown as the following.

$$
(I / A)^{2} / \sigma=\rho C_{P}(\mathrm{~d} T / \mathrm{d} t)
$$

where $\sigma$ is electric conductivity, $\rho$ is density, $C_{\mathrm{P}}$ is specific heat and $A$ is the area.

In the analysis of the solid armature, it is usually used to predict the thermal accumulation effect of material through the interaction integration, so the above equation is equivalent to the integral form

$$
\int_{t_{o}}^{t_{o}+\Delta t} I^{2} \mathrm{~d} t=A^{2} \int_{T_{O}}^{T_{O}+\Delta T} \sigma \rho C_{P} \mathrm{~d} T=A^{2} g
$$

where $g$ is material constant and the direct measurement of temperature increment, depending on the material property of armature. The material constant $g$ can be expressed in terms of the energy absorption $\Delta E$

$$
g=\Delta T \sigma \rho C_{P}=\rho \sigma \Delta E
$$

From what has been discussed above, the material selection of armature should consider three aspects:

(1) In order to minimize the armature mass, the density of armature have to be lower, so as to improve the efficiency of the transmission.

(2) The armature has the characteristics of high temperature resistant and higher energy absorption, aiming to increase the critical temperature of the transition of the contact points and prevent the arc.

(3) To reduce the production of the ohmic heating, the material of armature has better be electric excellently.

\subsection{Rail}

There is a direct relationship between the performance, service life, reliability and the cost and the material of railgun.

The heat conduction between the armature and rails is the decisive factor for the temperature rise of rails. Generally, the material selection of rail can use the mature formula ${ }^{[3]}$.That is

$$
q t_{E}^{1 / 2}=\Delta T_{S} \sqrt{\pi \rho C_{P} k}
$$

where $q$ is heat flux, $t_{\mathrm{E}}$ is contact time, $k$ is thermal conductivity, $\Delta T_{\mathrm{s}}$ is temperature change of transient thermal shocking and $q t_{E}^{1 / 2}$ is Roche quality factor.Table1 provides typical values of some materials. The value can quantitatively describe the anti-melting performance of rails, the higher the numerical value, the stronger the anti-thawing ability.

Table1 typical values of some materials

\begin{tabular}{c|c|c|c|c}
\hline Materials & $\mathrm{Cu}$ & Mo & Graphite & $\mathrm{Al}_{2} \mathrm{O}_{3}$ \\
\hline$q t_{E}^{1 / 2}\left(\times 10^{7} \mathrm{ws}^{1 / 2} / \mathrm{m}^{2}\right)$ & 3.5 & 4.6 & 7.3 & 2.06 \\
\hline
\end{tabular}

For the comprehensive utilization of the material properties, the design of diffusing solid coating layer of molybdenum or graphite on the copper surface has become a new research direction.

Besides, Matthew selected materials of rails and armature using Ashby diagram ${ }^{[4]}$.The results show that it is contradictory to realize both the magnetic energy and the durability of the rails, but the mixed material structure may meet the requirements of the goals, and four kinds of possible mixed structures are proposed. As follows in Fig.3. Experiments show the (c) is relatively more appropriate, so the paper reviews the monolayer structure. 


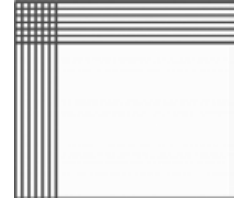

(a)Fibrous Composite

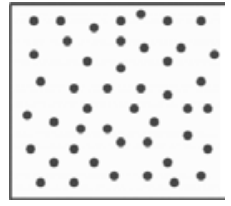

(b)Particulate Composite

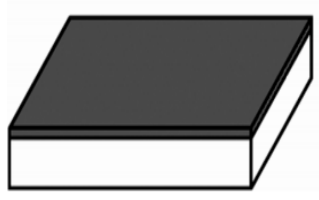

(c)Monolayer

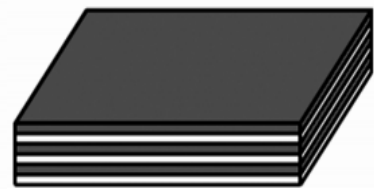

(d)Multilayer

Fig.3 Four possible mixed structures

\section{The Research Progress of Layered materials}

During the process of the electrical sliding contact between the armature and rails, the damage in the contact interfaces has an important effect on the condition of contact. Typical forms of damage are shown in Fig.4.The failure of the interfaces is closely related to the current distribution.Fig.5 shows the local current density is too

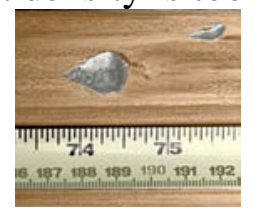

(a) gouge

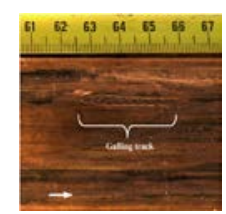

(b)galling track

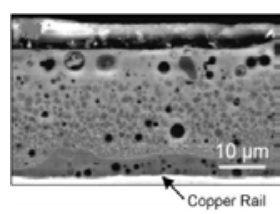

(c)erosion

Fig.4 Typical forms of damage
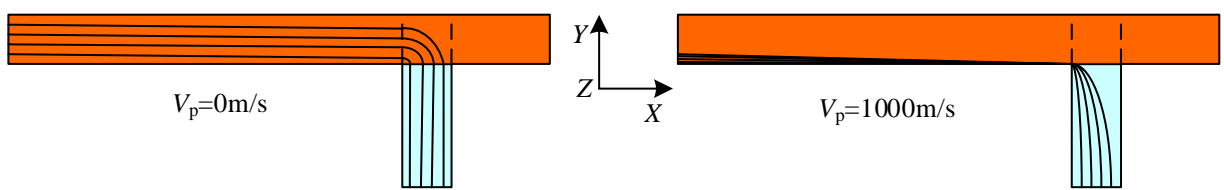

Fig.5 Current distribution caused by the velocity skin effect

large due to the velocity skin effect. When the velocity is more than $1000 \mathrm{~m} / \mathrm{s}$, the current is only concentrated in the $14 \%$ of the cross-section.

In order to make the current distribution uniformly, the early railgun researchers have designed a coated rail and layered armature. As is shown in Fig.6.
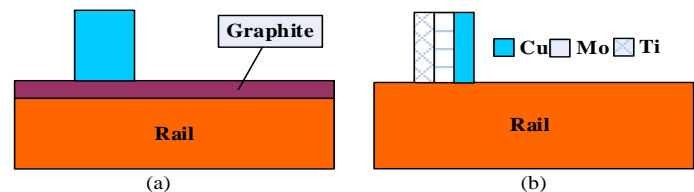

Fig.6 Structure with uniform current distribution

On the basis of the above, Gregory prepares two kinds of coatings of TiN and TaN on the surface of copper rails and $\mathrm{Al}$ armature using the techniques of ion implantation and ion beam assisted depositing ${ }^{[5]}$.Watt electroplates $2 \mu \mathrm{m}, 5 \mu \mathrm{m}, 25 \mu \mathrm{m}, 50 \mu \mathrm{m}$ Al coatings on the surface of UNS C15725, As is shown in Fig.7. It is found that the coatings can effectively inhibit the occurrence of gouge and wear through the actual test ${ }^{[6]}$.

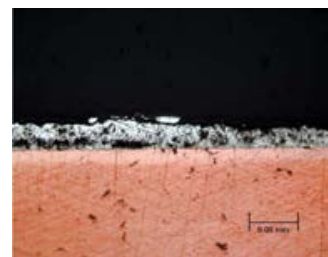

Fig.7 Orbital microscopic analysis of an electroplated aluminum layer

\section{Summary}

At present, the materials of rails widely are the copper alloy or composites and armature is aluminum with the lower density. However, the cooperation of these materials is still cannot meet the hypervelocity sliding and the wear resistance and anti-ablation and cannot follow up with the request of real combat without significantly reducing the thermal conductivity and electrical conductivity. Therefore, coating materials with excellent conductivity and resistance to high temperature erosion on the surface of rails and armature will be the new development direction, the 
most reliable way to solve the damage problems of railgun under different launching conditions.

\section{References}

[1] Q.A.Lv, B.Lin, Z.Y.Li and X.P.Chi. Summary of Electromagnetic Railgun Military Application. Journal of Gun Launch and Control, vol.1, 2009, pp.92-96.

[2] Holm R., Eletrical Contacts, Springer,New York,1979.

[3] Rosenwasser S.N, Stevenson R.D. Selection and Evaluation of Insulator Material for Performance Rail gun Bores. IEEE Transactions on Magnetics, vol.22, 1986, pp.1722-1729.

[4] Matthew J.S., Richard W.N. Materials Selection Exercise for Electromagnetic Launcher Rails. IEEE Trans Magn, vol.49, 2013, pp.4831-4838.

[5] G.R.Colombo, M.Otooni. Application of coatings for electromagnetic gun technology.IEEE Trans Magn, vol.31, 1995, pp.704.

[6] T.Watt, D.T.Motes. The effect of surface coating on the onset of rail gouging.IEEE Trans Plasma Sci, vol.39, 2011, pp.168. 